\title{
Analytical Study of the Extent of Practice and Implementation of Asei-Pdsi Approach by Teachers of Mathematics in Vihiga County, Kenya
}

\author{
Ayiego, E. M. ${ }^{1}$, Mang'are P. A. ${ }^{2,5}$, Ngome, C. K ${ }^{3}$, Mandilah, L. \\ ${ }^{1}$ School of Education, Mount Kenya University, Kakamega. Kenya \\ ${ }^{2}$ Physics and Mathematics Department, Moi University, Eldoret. Kenya \\ ${ }^{3}$ School of Education, Mount Kenya University, Kakamega. Kenya \\ ${ }^{4}$ School of Education, Mount Kenya University, Kakamega. Kenya \\ ${ }^{5}$ Physics Department, Egerton University, Egerton-Njoro. Kenya
}

\begin{abstract}
Perennial poor performance in Mathematics at National examinations has elicited concern by the Government of Kenya. This dismal performance was attributed to broad curriculum, lack of facilities, inadequate staffing, poor pedagogical approaches and lack of hands on activities. Mathematics, which is crucial in Kenya's realization of vision 2030, hampers its achievement. Studies have shown that interventions so far adopted had yielded negligible impact. The acronym ASEI stands for Activity, Students, Experiment, Improvisation whereas PDSI stands for Plan, Do, See and Improve, hence the ASEI-PDSI movement. Therefore, there was need to establish the extent of practice and implementation of ASEI-PDSI pedagogical approach in Vihiga County. This work established the preparedness of Stakeholders in their roles to implement the ASEI-PDSI movement; and the extent of practice of this approach. The data was collected using questionnaires and interview schedules; with principals, Heads of Mathematics department, teachers and Education officers as the respondents. The data was analysed statistically. The study ascertained the practice of PDSI approach, rated at 4.332 on a 5-point Likert scale, impacting positively on performance and attitude. There were improved teaching methodologies, improvisation of resources, and use of lesson rationale in Mathematics. It was noted that $95.89 \%$ of the teachers employed the ASEI approach. Also, $67.12 \%$ and $10.96 \%$ of the teachers improvised teaching and learning aids in the absence of the conventional ones mostly and always respectively. Teachers engaged students in varied activities in class and at home. However, $27.40 \%$ rarely improvised since $35.71 \%$ of the teachers were new in the profession or experienced burn out syndrome due to overstaying in a station or missed critical SMASSE (strengthening of mathematics and science in secondary education) cycles. The study showed that $97.26 \%$ of the teachers had schemes of work, affirming the importance of the tool for planning in any teaching and learning setup. The schemes of work were always used by $45.83 \%$ and mostly used by $40.28 \%$ of the sample respondents. However, $12.50 \%$ used them rarely. These results need to inform stakeholders on effectiveness of the SMASSE in-service education training and make a follow up with a view of strengthening the Programme.
\end{abstract}

Keywords: Pedagogy, Stakeholders, Instructional Materials, Curriculum and Improvisation.

\section{LIST OF ABBREVIATIONS / ACRONYMS}

ASEI

$>$ BSPS

$>\mathrm{HOD}$

$>$ INSET

$>$ JICA

$>\mathrm{KNEC}$

$>\mathrm{NCST}$

$>$ PDSI

$>$ QASOs
Activity, Students, Experiment, Improvisation

Basic Science Process Skills

Head of Department

In-service Education and Training

Japan International Co-operation Agency

Kenya National Examination Council

National Council for Science and Technology

Plan, Do, See, Improve

Quality Assurance and Standards Officers

\footnotetext{
*Corresponding Author: philipamuyunzu@gmail.com
} 
American Research Journal of Mathematics, Volume 1, Issue 2, April 2015

ISSN 2378-704X

$>$ SMASSE Strengthening of Mathematics and Science in Secondary Education

\subsection{Background Information}

The National Development Policy of Kenya aims at achieving industrialization by the year 2030 [10]. Mathematics, a core subject in the Kenyan secondary schools Education has been re-emphasized due to its role in placement, industrial and technological development [12]. However, the performance in Mathematics and Science which the industrialization relies upon has been poor. The improvement of Mathematics and science was, therefore, considered as a matter of urgency in Kenya. An intervention by JICA and the Government of Kenya established SMASSE Project (Phase I) in 1998. The aim of SMASSE project was to strengthen Mathematics and the Science subjects through In-Service Training (INSET) for teachers and upgrade the capability of students in Kenyan secondary schools in Mathematics and Science subjects [33]. SMASSE also intended to develop good work plan through ASEI/PDSI approach as a way of ensuring well utilization of available resources in terms of money and time and identifying ways of creating and sustaining interest [16]. During the Phase I Project a system of training District Trainers at the National INSET Centre, and training in pilot districts were established. Also, the roles of the National INSET Centre and District INSET centres were strengthened.

A baseline survey conducted in nine pilot districts: Kajiado, Gucha, Kakamega, Lugari, Butere- Mumias, Kisii, Muranga, Maragua and Makueni by SMASSE personnel in 1998 showed that attitudinal factors, poor teaching methodology, lack of mastery content, lack of a professional forum for teachers to share their experiences, inadequate development of appropriate teaching and learning materials and administrative factors were responsible for poor performance in Mathematics at secondary level ([22], [30], [32]). Teachers' poor attitude was attributed to the reluctance to engaging learners in "hands on" activities during the learning process [14]. This indicated that teachers of Mathematics needed to move away from traditional models of instruction and embrace modern theories of teaching as advocated by the ASEI-PDSI approaches. The Student-Centered Experiment and Improvisation (ASEI) Approach considered quality of classroom activities as critical to achieving effective teaching and learning and hence good performance in Mathematics [35]. These are meaningful hands on (manipulation), minds-on (intellectual thinking, reasoning) mouths-on (discussions), heart-on (those that stir up the learners' interest or feelings about the subject) activities. ASEI-PDSI approach stressed on the need for the learners to carry out a well planned learning activity that involves seeing and improving the activity hence promoting effective learning to take place [42]. The ASEI-PDSI initiative focuses on teachers to reflect on their teaching strategies and acquire skills for effective teaching and efficient learning to occur [30]. The ASEI - PDSI movement was meant to assist teachers reflect on their teaching methods and acquire skills for effective teaching that could lead to efficient learning [13]. This was because ASEI-PDSI recognized that meaningful learning takes place in an environment in which students are actively engaged in focused and sequenced activities for acquisition of knowledge and skills ([22], [24], [30], [33]). Through improvisation, the teachers were able to demystify conventional activities by scaling down experiments, thereby relating Mathematics to real life situations. A bridge was created to enable learners to relate and integrate practical activities with theoretical knowledge [24].

The ASEI/PDSI approach to teaching attracted many other districts previously not covered by the Project, Vihiga coming on board in 2004. This effective method of teaching Mathematics emphasizes on students' participation from the start of the lesson up to the end ([30], [42]). The project strengthened the networking and collaboration among teachers to enable exchange of experiences related to teaching Science and Mathematics. Teacher competence was addressed through working on the following areas: attitude, teaching methodology, mastery of subject content, developing of teaching and learning materials besides issues of school management [18]. Student centered approaches, based on experiments and improvisation are emphasized alongside the need for teachers to evaluate every aspect of the lesson during teaching. Furthermore, the need for the learners to carry out well planned learning activities that involves seeing and improving was stressed. It is argued that an object well handled practically impresses itself more firmly in the mind than the object merely seen from a distance or in an illustration [42].

Findings of recent researches on teaching interventions in Mathematics, SMASSE and ASEI-PDSI approach to teaching of Mathematics in relation students achievement based on gender, therefore had similarities with this study, in that they all sought to establish classroom practices and strategies in Mathematics classrooms which led to higher achievement in both boy and girl students ([3], [8], [11], [18], [26], [27], [28], [38] , [39] , [41]).

Teachers are challenged to be creative and also improvise in Mathematics classrooms, school managers are encouraged to mobilize resources towards improving the teaching, learning and performance of Mathematics while the role played by quality assurance and standards officers is reaffirmed [31]. 
In view of the foregoing, SMASSE centres were established where mathematical apparatus and equipment can be borrowed by schools that do not have enough or lack totally with the aim of encouraging "hands on" approach in learning of Mathematics. In spite all this effort, the performance in Mathematics in the Country at KCSE level is still poor [21].

Classroom practices in Mathematics involve a process which is dependent on attitude of the teacher, material channels, feedback, students' abilities, attitudes of students, class size and school environment ([5], [9], [14]). Teacher competence and practices in class are pivotal in students' achievement in Mathematics and have contributed to the design of national curricula in the world putting emphasis on pedagogical issues in the teacher training programs, measurement of pupils' achievement and availability of resources ([11], [17]). These aspects which have been identified and improved upon at different levels contribute towards effective teaching and learning of Mathematics [36], hence making Mathematics concepts popular with the learners.

This is from the realization of the benefits that Mathematics holds for both the individual and the society. Mathematics takes a central role in secondary school curriculum because of its nature of relating and providing meaning to other subjects in the curriculum and for career diversification. The society benefits from general Mathematics literacy of its population in ways such as people will have a better understanding of related fields such as science and its nature; business and economics and associated policies, and their contribution towards the attainment of Kenyan vision 2030.

Dismal performance in Mathematics at National and County level by girls had been confirmed by recent reports from KNEC, a situation that had contributed to overall poor performance of KCSE Mathematics examinations. More so, the performance in Mathematics in Vihiga County had been poor, recording a mean of 2.73 out of twelve in 2007 due to mass failure by girls [7]. In view of the foregone, this study sought to establish the role preparedness of the stakeholders and the extent of practice and implementation of ASEI-PDSI approach by teachers of Mathematics in Vihiga County. The application of ASEI-PDSI approach was determined by the level and appropriateness to which activities in the classroom were planned, student involvement, engagement of students in manipulative skills and the extent of improvisation in Mathematics classrooms. Teacher acquaintance and dedication to the format of planning, content delivery in classroom through doing, seeing as the learners relate with Mathematics knowledge and improving on the entire process was also established. The outcomes of this study provided the stakeholders with factual information on the effectiveness of SMASSE through application of the ASEI-PDSI in improving performance in Mathematics to stakeholders in Vihiga County, Kenya.

\subsection{Statement of the Problem}

The performance in Mathematics has over the years been dismal and on a steady declining trend nationally, yet the subject is essentially critical in course placement in fields such as medicine, engineering, architecture, agriculture and commerce, technological achievement and professional education. The dismal performance locked out students from coveted courses since it is compulsory to all students at both Primary and Secondary level. A national analysis of Mathematics KCSE results for the years 2000-2005 confirmed the above assertion, with $81 \%$ recording poor results; boys and girls attaining a mean score of $22.10 \%$ and $16.05 \%$ respectively in the six years ([20], [21]). The dismal performance was attributed to inadequate coverage of the syllabus, lack of practice, and mastery of basic Mathematics concepts [19]. Teachers play a critical role in teaching and learning of Mathematics because they were the actual implementers of the curriculum; and a primary source of instruction in most societies and forms classroom organization [40]. The SMASSE baseline studies enlisted attitudes towards Mathematics and science, inappropriate teaching methods and low content mastery as major problems in Mathematics [29]. Many efforts to reverse the trend have been undertaken with minimal impact. SMASSE, with its ASEI-PDSI approach took roots in Vihiga County in the year 2004. SMASSE had been declared in the seventh National development plan of Kenya to establish industrialization [18]. Despite the fact that teachers have been trained both at colleges and in SMASSE INSETs, the performance in Mathematics at KCSE is still low with disparity in gender. Studies have been conducted on the student's poor performance in Mathematics in Vihiga County but no studies have been conducted to establish the role preparedness of the stakeholders and the extent of practice and implementation of ASEI-PDSI approach by teachers of Mathematics in Vihiga County. The research established role preparedness of stakeholders and the extent of application of ASEI-PDSI approach through the use of questionnaires and interview schedules; and analysed statistically.

\subsection{Objectives}

\subsubsection{General Objective}

To establish the role preparedness of the stakeholders and the extent of practice and implementation of ASEI-PDSI approach by teachers of Mathematics in Vihiga County. 
American Research Journal of Mathematics, Volume 1, Issue 2, April 2015

ISSN 2378-704X

\subsubsection{Specific Objectives}

The following were the specific objectives of the study:

To establish the preparedness of Stakeholders in their roles to implement the ASEI-PDSI

To determine the extent of practice of the ASEI movement approach in teaching and learning of Mathematics

To assess the extent of implementation of PDSI Approach in teaching and learning of Mathematics

\subsection{Research Questions}

The following research questions were used to guide the study:

A Are the stakeholders prepared in their roles of implementing the ASEI-PDSI approach?

To what extent are teachers of Mathematics practicing the ASEI approach in teaching and learning.

To what extent are teachers of Mathematics practicing the PDSI approach in teaching and learning.

\subsection{Significance of the study}

The findings of the study would be useful in the following ways:

Help the District planning committee (DPC) in assessing the effectiveness of the SMASSE INSET implementation at the district level.

Assist Quality Assurance and Standard officers (QASOS) both at the district and the national levels in making follow up of SMASSE INSET with a view of giving more advice and guidance to teachers of Mathematics on how to improve on their teaching approaches and methodology.

The findings of this study were to improve on the performance of boys and girls at KCSE in Mathematics in secondary schools in Vihiga County.

\subsection{Scope and Limitations of the study}

The study was conducted in Vihiga County which currently has a total of 125 secondary schools. This area was selected based on the fact that it hosts two major SMASSE centres which have recorded exemplary performance in the implementation of SMASSE programmes and activities. The research also confined itself to the practice and implementation of ASEI-PDSI approach in the teaching and learning of Mathematics.

\subsection{Assumptions of the Study}

The study made the following assumptions:

All the Stakeholders in Vihiga County had been fully prepared of their roles for effective implementation of the ASEI-PDSI movement.

$>$ All teachers of Mathematics had embraced the practice of the ASEI movement in teaching and learning of Mathematics.

The PDSI teaching and learning approach was being implemented by all teachers in teaching and learning of Mathematics

\subsection{Theoretical and Conceptual Framework}

Recent works show that learning occurs through the process of observation [1]. In any given environment, observation of objects and individuals he referred to as models contributes to the learning outcomes. He further observed that learners pay attention to some of these models and encode their behavior. At a later time, learners may imitate the behavior they have observed regardless of whether it is gender appropriate or not. More likely, a learner will reproduce the behavior that the society considers appropriate for its gender especially if the learner imitates a models behavior and the consequences are rewarding ([4], [15]).

In applying Albert Bandura's Social Learning Theory in this study, teachers were looked at as models by their learners and through extensive and conscious planning on the part of the teacher followed by elaborate implementation of the plan in a well prepared environment; problem solving abilities were transferred to the learner [25]. Teachers' level of preparation, delivery and motivating of learners as advocated by ASEI-PDSI approach in 
Mathematics was likely to contribute to the learners' behavior as exhibited through learners' interests, learners' performance in examinations and future careers that were to be pursued by the learners. Teachers' approaches in Mathematics classrooms through effective application on ASEI- PDSI approach as advocated through SMASSE INSETs would determine the level to which students understood Mathematics hence learners achievement as shown in Figure 1.1.

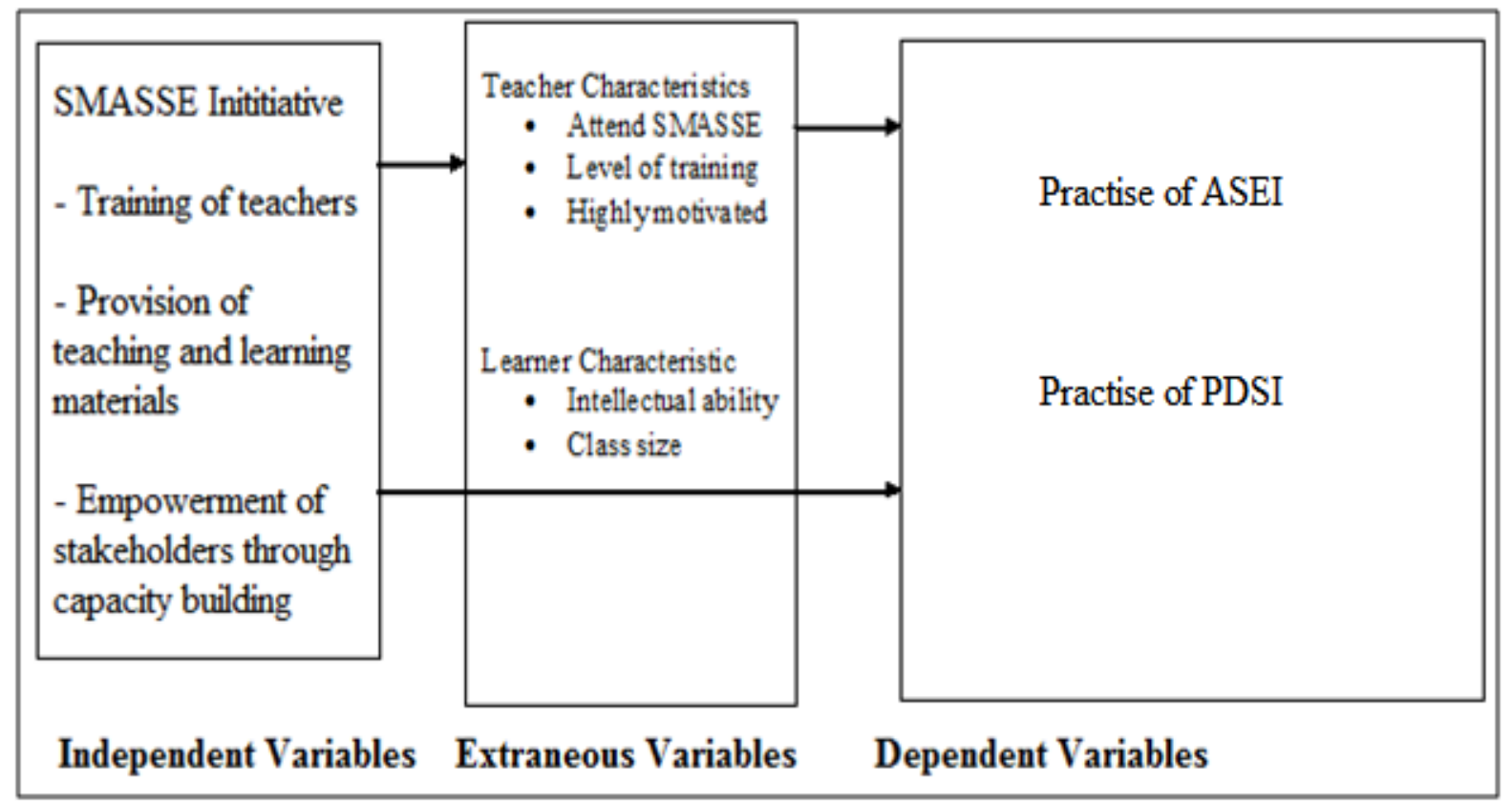

Fig1.1 The Practice of ASEI- PDSI Approach Dependent on SMASSE initiative

\section{ReSEarch Design AND Methodology}

\subsection{Research Design}

The descriptive survey research was intended to produce statistical information about aspects of education that interest policy makers and educators. The survey research was therefore useful because of the economy of taking a sample of the population to generalize results for the whole population. The survey involved collecting information by interviewing or administering a questionnaire to a sample of individuals ([2], [6], [34], [37]).

\subsection{The Study Area}

Vihiga County has consistently recorded dismal performance in Mathematics with a worrying trend in gender disparity compared to the neighbouring Counties. The quality grades in Mathematics have also been seldom with very few students enrolling in competitive and coveted careers. This premise determined the Choice of Vihiga County as the study area. Vihiga County borders Nandi County to the north, Kisumu County to the East, Siaya County to the southwest and Kakamega County to the West. Vihiga has four Districts namely Vihiga, Emuhaya, Hamisi and Sabatia. There are three SMASSE training centres in the County. These are Bunyore Girls High School, Moi Girls High School -Vokoli and Kaimosi Girls High School. The County has seen an explosion of school population, currently standing at 125 secondary schools. A majority of the schools are mixed.

\subsection{The Study Population}

Vihiga County has about 125 secondary schools with a total of 8 Boys', 12 Girls' and 105 mixed secondary schools all distributed in the four districts of Vihiga County. A sample of $30 \%$ of the schools in the County was selected for the study. The schools in the County were categorized into boys' boarding schools, girls' boarding Schools and Mixed Schools thereafter randomly selected.

To calculate the number of sampled schools by category, the total number of schools in each category was multiplied by the ratio of schools sampled to the total number of secondary schools in the County. From a total of 38 schools to be sampled, 5 Boys, 8 Girls and 25 mixed schools were selected to ensure adequate representation. 
The research targeted 38 Principals and 38 Heads of Mathematics department, 136 teachers of Mathematics and three education officers in Vihiga County as respondents.

\subsection{Sample and Sampling Procedures}

The samples of this study comprised of 38 Principals, 38 HOD's of Mathematics, 136 teachers of Mathematics in public secondary schools and three Education officers in Vihiga County. Their choice was based on the assumption that they have a longer experience in teaching and management of schools. Sample of 38 schools (30\%) from a sample space of 125 was used comprising of Girls, Boys and mixed Schools. This figure was arrived at by using a generalized scientific guideline for sample sizes [23]. Five Boys' schools, eight Girls' school and 25, Mixed schools were selected using simple random sampling. This was done by placing the names of schools in a container, shaking and then picking the required number of schools randomly.

\subsection{Study Variables}

Both independent variables and the dependent variables were used in the study. Independent variables included SMASSE initiative through training of teachers, provision of teaching and learning resources and empowerment of stakeholders through capacity building. The dependent factors included the practice of ASEI and PDSI approaches. The characteristics of teachers and students constituted extraneous variables.

\subsection{Research Instruments}

In the study, the Principals questionnaire, questionnaire for Heads of Mathematics department, teachers' questionnaires and interview schedule for education officers in the county were the instruments for the research. The instruments were used to supplement each other and to give a deeper and wider exploration into research perspective in order to enhance the research quality.

\subsubsection{Principals' Questionnaire, Questionnaire for HODs' of Mathematics and Questionnaire for Teachers of Mathematics}

The Principals' Questionnaire, Questionnaire for HODs' of Mathematics and Questionnaire for Teachers of Mathematics sought information on the practice and implementation of the ASEI-PDSI movement.

\subsubsection{Interview Schedule for Education Officers}

Interview schedule on the study were designed and administered to education officers in the County.

\subsection{Piloting of Research Instruments}

A pilot study was conducted in two secondary schools which were randomly selected from the County in order to validate the research instruments and also test the reliability of the instruments. These schools were not among the sampled schools. Two Principals, two HODs of Mathematics and four teachers of Mathematics were involved in the pilot study. Purposive, followed by simple random sampling were used to pick one class or stream for purposes of observation per school.

\subsubsection{Reliability of Instruments}

This study employed the test-retest method to establish the consistency with which the research instruments yielded same information on repeated attempts. Research instruments were administered in the pilot schools; scored manually; then administering the same instruments to the same group of subjects after two weeks and scoring the instruments manually again; then comparing the responses obtained in the two occasions. Pearson's product moment correlation coefficient was computed in order to determine the extent to which the research instruments were consistent in eliciting the same responses every time the instruments were administered. A correlation coefficient of 0.78 was obtained for the Mathematics teachers' questionnaire, 0.80 for Heads of Mathematics questionnaire and 0.84 for the Principals' questionnaire. The research instruments were hence accepted as being reliable.

\subsubsection{Validity of the Instruments}

The teachers of Mathematics, Heads of Mathematics departments and Principals of pilot schools helped in determining the content validity of the research instruments. The researcher's supervisors also determined the validity of the research instruments. The recommendations of the supervisors and those of the Principals, HODs and teachers of Mathematics of the pilot schools were incorporated in the final research instruments. 


\subsection{Data Collection and Analysis}

The researcher obtained a letter of introduction from the Graduate School, Mount Kenya University and took it to the National Council of Science and Technology (NCST) to obtain a research permit. The researcher then visited the County Commissioner and County Director of Education to inform them of the intended study and seek their clearance. An authorization letter allowing the study to proceed was issued. The research instruments were personally administered by the researcher in all the sampled schools. The data from the questionnaires was manually analyzed using both descriptive and inferential statistical techniques. The descriptive presented the results as means and percentages. To get the mean score for each aspect in the tables, the number of respondents for the aspect was multiplied by their "weightage" rank, added up and divided by the total number of respondents. To get the average score for a component, the mean scores of indicators or aspects are added up and divided by the total number of indicators or aspects. The findings were presented and discussed according to themes derived from the objectives of the study. Percentages and means were employed for the descriptive statistics.

\section{Data Analysis, Presentation and Discussion of Results}

Effective practice of ASEI-PDSI is dependent of personnel competencies and preparedness. The study first sought to establish the specific roles of all the stakeholders and if at all they had been exposed to the training essential for the implementation of SMASSE programme through ASEI-PDSI movement.

\subsection{Roles of Stakeholders and Capacity Building}

The practice of ASEI-PDSI in classroom required a consolidated effort from all stakeholders. The study established that Principals had been prepared adequately through mounting of SMASSE workshops. Out of the sampled Principals, $71.43 \%$ reported to have attended SMASSE workshops, which was a considerable figure. The Principals observed many benefits and relevance in knowledge and skills emanating from SMASSE training workshops and capacity building to all stakeholders. These benefits included being enlightened on the whole concept of SMASSE and being fully prepared for its activities enforcement in schools. The training was noted to provide a forum for Principals to share ideas on SMASSE, although it was limited to aspects of supervision for nonMathematics principals. The principals reported that the hands on experience through the ASEI approach promoted students participation thus yielding learners centeredness in the teaching and learning of Mathematics. The principals were also provided with an insight into the role of the principals in the teaching and learning of Mathematics which was critical in their management roles. The exposure to essential learning and teaching activities in Mathematics placed them an edge higher in enforcing the approach in their respective schools. In order to achieve good results in Mathematics, it was suggested that head teachers needed to listen and attend to teachers' requests as they go a long way in enhancing learning.

This research also sought to establish whether the Principals and heads of Mathematics departments knew their roles as related to the implementation of the ASEI-PDSI approach. The specific roles of head teachers in SMASSE programmes and activities as obtained from the study included: purchasing of required apparatus, compiling and receiving of SMASSE related reports, resource mobilization, facilitate acquisition of teaching resources, provision of required materials for students activities and guidance in the utilization of those resources. It was indicated that principals needed to use facts in handling teachers, be role models in SMASSE activities by ensuring that teachers of Mathematics implemented what they learnt from INSETs. These could be realized through active participation for both teachers and students in SMASSE activities. They Principals are expected to facilitate all teachers of Mathematics to attend SMASSE INSETs and thereafter oversee the implementation of SMASSE activities at school level. Remittance of financial support towards SMASSE and funds allocated by Ministry of Education was a major role of principals since it enhanced the success of the SMASSE activities in the County. It was within the principals' jurisdiction to allow teachers of Mathematics to attend SMASSE INSETs.

The schools in Vihiga County reported that they had seldom received instructional materials from the SMASSE centres. However, $9.5 \%$ of the principals acknowledged receiving the materials from the three centres: Moi Girls high school- Vokoli 1, Kaimosi Girls' high school and Bunyore Girls' high school. Teachers who sourced the materials from the SMASSE centres reported that the materials made Mathematics easier to many students. Some indicated that they acquired materials such as LCD projectors and softwares for simulation of concepts in Mathematics class. However, others only got them for students use in Science and Engineering Fare. The teachers who have not explored this avenue may have not known the procedures of getting such materials. On the other hand, the teachers had become very innovative as reflected in their affirmation. Worth noting is the fact that $78.08 \%$ of 
the teachers sampled indicated that they mostly and always improvised teaching and learning materials in the absence of the conventional ones.

In terms of attendance, $95.24 \%$ of the heads of Mathematics department attended SMASSE workshops and argued that the SMASSE workshops and INSETs had been relevant and essential in teaching and learning of Mathematics. It was noted that the SMASSE workshops and INSET's had improved on teachers' attitude which was cascaded to learners' attitude. They appreciated that the training provided an approach that was friendly to learners hence making the subject enjoyable to all students. It also proved that emphasizing on application created a desire in the student to know. Moreover, students' discussions yielded confidence in them. During the training, it was indicated that topics facilitated included ICT integration in classroom lessons and acquisition of softwares and other facilities. Concepts and skills learnt in SMASSE helped to enlighten teachers on the essentiality of involving the students in the learning process. It showed that teaching activities offered during the INSET's were very relevant to the teaching and learning of Mathematics through ASEI-PDSI approach hence increasing on the number of quality grades. It was reported that teachers of Mathematics had become very innovative, thus enhancing the use of activities that made Mathematics simple to understand for the learners. In order to effectively implement the SMASSE programme in Vihiga County, it was important that the teachers who had not fully or partially trained be facilitated to acquire the ASEI-PDSI skills. As HODs of Mathematics, they acknowledged their different roles in regard to SMASSE programmes and activities schools. They argued that their duty was to spearhead internal Mathematics symposium and allocate sufficient time on the timetable for the activities of Mathematics in school. The HODs coordinated the improvisation of the three dimensional models essential in teaching and learning of Mathematics hence promoting student centeredness. The HODs and also as teachers had to oversee the implementation of ASEI-PDSI approach in class and collectively come up with strategies that will improve on pedagogy. They also ensured proper planning and effective delivery of Mathematics syllabus in all the classes by collectively coming up with strategies that see Mathematics taught well. The HODs viewed their roles as majorly aiding the implementation of ASEI-PDSI in teaching and learning of Mathematics and supervising the actual teaching and learning of Mathematics. Also, they encouraged the use of lesson plans and teaching aids, group discussions among students, implementation and redesigning of policies governing Mathematics. This ensured that lessons were covered in all classes using appropriate methods according to the new policy. They also supported in coordinating and writing schemes of work and ASEI lesson plans, supervising the implementation of the curriculum and syllabus coverage in compliance with the schemes and SMASSE training. The HODs acknowledged that the responsibility of approving and forwarding requests for acquisition of teaching and learning resources recommended by SMASSE was vested in their hands.

Failure of some teachers to attend the SMASSE INSETs hindered effective use of the ASEI-PDSI approach. The teachers forwarded official school duties and commitments or studies on school based programmes at the University or colleges as their excuses. Some teachers were noted to lack interest and assumed that they knew it all, while some had personal commitments at family level. Others were newly recruited teachers who seemed not to view its relevance since they were not regular in school as most of them may be employed by B.O.G.

It was also reported that the teachers who attended SMASSE INSET's had greatly influenced the attitude of learners towards Mathematics in a number of ways that included teaching the subject in a learner centered manner. They employed team-teaching depending on the topics of interest and talent.

The teachers gave teaching approach of Mathematics a real life application. They promoted regular practice in Mathematics and consultation in areas of difficulties. Through application of ASEI-PDSI in teaching and learning of Mathematics, the learner's participation was enhanced. The teachers integrated ICT where some Mathematics concepts were perceived to be hard or too abstract thereby making them simple. Regular motivational talks and interaction during discussion had instilled confidence yielding high achievement. It was suggested that teachers should allow girls to participate through solving questions on the board and demonstrations. Most of the learning was purely learner centered; hence learners were easily controlled during lessons. Their self driven attitude level was estimated to be $78 \%$ implying that both the learners and the teachers' attitude was positive. The improvement witnessed in the recent KCSE results in Mathematics was an indication of the influence of SMASSE. The use of improvisation and career centered approach in teaching and learning of Mathematics had had a positive impact. The teachers who attended the INSETs had embraced the learner-centered approach which had enabled students to view Mathematics as a possible subject.

This research established that the teachers of Mathematics who attended SMASSE INSETs were professionally different from those who did not attend the training due to skills and knowledge acquired. The teachers were noted to have understood the relationship between attitude and performance in Mathematics, hence endeavored to promote 
positive attitude among teachers and learners. They also made lessons more leaner and teacher friendly through improvisation of teaching and learning materials. Teachers also applied the new methodologies and approaches learnt in SMASSE INSETs in teaching. Such approaches encompassed formulation of activities which enhanced students' participation making the subject very interesting and enjoyable to the learners. That, in effect, changed the attitude of the learners towards Mathematics hence leading to improvement in performance. It was observed that teachers of Mathematics learnt new approaches which included the use of ASEI-PDSI teaching method. The ASEIPDSI approach involves more creativity that makes subject practical oriented. There is also use of hands on activities with a student centered approach through innovativeness resulting to improved performance in Mathematics. These teachers, who had undergone the SMASSE INSETs prepared thoroughly and worked professionally. They prepared and used the ASEI-PDSI lesson plans and knew how to involve the usage of stimulus variation in their class work. They have also influenced other teachers in the school since they acted as role models through display of demonstration on how to integrate ICT in their lessons and how to source for information from the internet thus positively inducting new teachers in the INSET.

The teachers of Mathematics were reported to assist their colleagues in lesson preparation strategies thus collectively improving on teachers' attitude towards Mathematics, lesson preparation, and lesson quality and delivery. Through sharing of experiences, teachers provided direction on handling of different topics in Mathematics. This was done through the use of practical approach, emphasis on students' guided activities in Mathematics which involved group discussions and learner participation across the board. All these approaches enhanced positive change thus yielding better results.

\subsection{The Practice of ASEI Approach by Teachers of Mathematics in Vihiga County}

It was observed that $95.89 \%$ of the teachers employed the ASEI movement practices in the teaching and learning of Mathematics. It was also noted that all teachers engaged students in classroom activities during the lesson. Teachers who practiced ASEI movement engaged learners in formulating group and class discussions where they assigned specific topics to students which they researched on and taught other students during the same discussions or class presentations. The teachers also gave extra activities to students such as assignments during the lesson which was done as homework, frequent exercises in books and later on or during the next lesson the questions are attempted on chalkboard. Experimentations and improvisation were simple techniques used by teachers in Mathematics lessons in order to promote understanding of concepts. This approach involved activities such as making of models, opening of nets, determination of pi $(\pi)$ using cans, using splints to develop sequence, filling puzzles, counting, taking notes; demonstration such as throwing of discs and tossing coin; playing cards in addition and subtraction of integers, use of charts and skits, drawing graphs and use of hands on activities where the apparatus are available or improvised. Also, activities such as field activities and project work were normally done through data collection and analysis supervised by the teachers.

Finally, evaluation was another activity in ASEI movement which involved giving of Mathematics examinations or tests to the students. Evaluation was also done after each topic or lesson by giving assignments particularly for lesson evaluation. The teachers who practiced the ASEI movement also engaged students' in setting and marking of the Mathematics examinations.

It was established that $67.12 \%$ of the teachers improvised teaching and learning aids in the absence of the conventional ones mostly and only $10.96 \%$ did it always. However, $27.40 \%$ rarely improvised. As earlier reported, this was due to many teachers $(35.71 \%)$ who are still new in the profession or due to burn up syndrome resulting from overstaying in a station. Also, some might have missed cycles related to ASEI, essential for improvisation. As earlier reported, the teachers' experience was significant in predicting students' performance in Mathematics. Similarly, the teachers' attitude towards the teaching of Mathematics also played a significant role in shaping the attitude of students towards the learning of Mathematics [42].

\subsection{The Practice of PDSI Approach by Teachers of Mathematics in Vihiga County}

PDSI as earlier alluded is an acronym of Planning, doing, seeing and improving ([30], [22], [33]). This approach stresses on the need for the learners to carry out a well planned learning activity that involves seeing for themselves and improving the activity even further for effective learning to take place [42]. The PDSI approach is the means of realizing the ASEI movement discussed in 4.4.2. This research established that departmental schemes of work for Mathematics in line with the current syllabus were available among $97.26 \%$ of the respondents. However, $2.74 \%$ of the teachers did not have the schemes of work. Schemes of work are an important tool for planning in any teaching and learning set-up. It was observed that schemes of work were always used by $45.83 \%$ of the sample 


\section{American Research Journal of Mathematics, Volume 1, Issue 2, April 2015}

ISSN 2378-704X

population studied. The study also revealed that $40.28 \%$ used the schemes mostly with only $12.50 \%$ using them rarely. It was also observed that $1.38 \%$ of the teachers involved in the study never used the schemes of work.

In this study, questionnaires were administered to teachers so as to get information on what goes on in classroom during a Mathematics lesson and the implementation of ASEI-PDSI. The aim was to gauge the teachers' implementation of the new skills acquired and the new approach to teaching of Mathematics. There were 15 items in the teachers' questionnaire based on a 5- point scale regarding aspects of Mathematics lesson depicting PDSI as indicated in Table 3.1.

Table3.1. Response Statements on Likkert Scale

\begin{tabular}{|l|l|l|}
\hline RESPONSE & ABBREVIATION & POINTS \\
\hline Strongly agree & SA & 5 \\
\hline Agree & A & 4 \\
\hline Not sure & NS & 3 \\
\hline Disagree & D & 2 \\
\hline Strongly disagree & SD & 1 \\
\hline
\end{tabular}

The data, shown in Table 3.2, was collected from the teachers of Mathematics in the sample schools in Vihiga County. The data collected was analysed using the following formula in order to get the grand mean result:

Table 3.2 Field Results on the Practice of PDSI in Schools - Vihiga County

\begin{tabular}{|c|c|c|c|c|c|c|}
\hline & & \multicolumn{5}{|c|}{ SCALE } \\
\hline & & 5 & 4 & 3 & 2 & 1 \\
\hline ASPECT & STATEMENT & SA & $\mathbf{A}$ & NS & D & SD \\
\hline \multirow{5}{*}{$\mathrm{P}$} & I strive to overcome misconceptions during Mathematics lesson. & 45 & 24 & 1 & 2 & 0 \\
\hline & Students enjoy Mathematics lesson & 9 & 24 & 7 & 4 & 0 \\
\hline & $\begin{array}{l}\text { Every lesson of Mathematics has a rationale which is gender } \\
\text { sensitive }\end{array}$ & 13 & 29 & 16 & 11 & 2 \\
\hline & $\begin{array}{l}\text { I avail prerequisite teaching and learning materials before the } \\
\text { lesson }\end{array}$ & 19 & 45 & 2 & 4 & 0 \\
\hline & $\begin{array}{l}\text { I ensure that the students have all the prerequisite knowledge } \\
\text { before the lesson }\end{array}$ & 24 & 39 & 2 & 2 & 0 \\
\hline \multirow{5}{*}{ D } & I strive to be innovative in my lesson presentation. & 45 & 27 & 0 & 0 & 0 \\
\hline & I employ varied teaching methods to enhanced understanding. & 39 & 31 & 1 & 0 & 1 \\
\hline & I am not a monopoly of information in class. & 44 & 24 & 1 & 1 & 0 \\
\hline & I strive to positively reinforce the student's responses. & 41 & 31 & 0 & 1 & 0 \\
\hline & I motivate girls to participate in class activities. & 48 & 20 & 1 & 1 & 0 \\
\hline \multirow{4}{*}{$\mathrm{S}$} & Other teachers attend my Mathematics lessons. & 12 & 33 & 5 & 20 & 4 \\
\hline & I allow my peers to critique my lesson. & 18 & 35 & 7 & 7 & 1 \\
\hline & I respond to students challenges promptly. & 41 & 31 & 0 & 0 & 0 \\
\hline & I involve boys and girls in Mathematics lesson activities & 43 & 22 & 5 & 1 & 0 \\
\hline \multirow{3}{*}{ I } & $\begin{array}{c}\text { I strengthen the effective instructional delivery practices in my } \\
\text { lesson. }\end{array}$ & 40 & 31 & 2 & 0 & 0 \\
\hline & I correct previous lesson mistakes immediately & 40 & 31 & 0 & 1 & 0 \\
\hline & I strive to improve on student performance & 56 & 17 & 0 & 0 & 0 \\
\hline
\end{tabular}

Where

$\mathrm{n}$-Number of respondents that agreed with the statement

$\mathrm{s}$ - The score on scale

$\mathrm{x}$ - Total number of respondents

$y$ - Number of statements 
The analysis of all the 15 items gave a grand mean $M=4.332$. The results are shown in Table 3.3. The results clearly show that teacher's teaching approaches had agreeably improved as a result of SMASSE. There was only one item which showed some weaknesses on the side of teachers where they seemed not to allow other teachers to attend their lessons. However, this was attributed to staffing challenges.

Table3.3. Analysis of Teachers' Response to the Practice of PDSI in Classroom

\begin{tabular}{|l|l|l|l|}
\hline ASPECT & STATEMENT & TOTAL & MEAN \\
\hline P & I strive to overcome misconceptions during Mathematics lesson. & 328 & 4.5556 \\
\cline { 2 - 4 } & Students enjoy Mathematics lesson & 170 & 3.8636 \\
\cline { 2 - 4 } & Every lesson of Mathematics has a rationale which is gender sensitive & 253 & 3.5634 \\
\cline { 2 - 4 } & I avail prerequisite teaching and learning materials before the lesson & 289 & 4.1286 \\
\cline { 2 - 4 } & I ensure that the students have all the prerequisite knowledge before the lesson & 286 & 4.2687 \\
\hline \multirow{5}{*}{ D } & I strive to be innovative in my lesson presentation. & 333 & 4.6250 \\
\cline { 2 - 4 } & I employ varied teaching methods to enhanced understanding. & 323 & 4.4861 \\
\cline { 2 - 4 } & I am not a monopoly of information in class. & 321 & 4.5857 \\
\cline { 2 - 4 } & I strive to positively reinforce the student's responses. & 331 & 4.5342 \\
\cline { 2 - 4 } & I motivate girls to participate in class activities. & 325 & 4.6429 \\
\hline S & Other teachers attend my Mathematics lessons. & 251 & 3.3919 \\
\cline { 2 - 4 } & I allow my peers to critique my lesson. & 266 & 3.9118 \\
\cline { 2 - 4 } & I respond to students challenges promptly. & 329 & 4.5694 \\
\cline { 2 - 4 } & I involve boys and girls in Mathematics lesson activities & 320 & 4.5070 \\
\hline \multirow{4}{*}{ I } & I strengthen the effective instructional delivery practices in my lesson. & 330 & 4.5205 \\
\cline { 2 - 4 } & I correct previous lesson mistakes immediately & 326 & 4.5278 \\
\cline { 2 - 4 } & I strive to improve on student performance & 348 & 4.7671 \\
\cline { 2 - 4 } & GRAND MEAN & & $\mathbf{4 . 3 3 2 0}$ \\
\hline
\end{tabular}

\section{CONCLUSIONS AND RECOMMENDATIONS}

\subsection{Conclusions}

The research established that all stakeholders had been trained to roll out the SMASSE project activities leading to success in its implementation. It was also noted that teachers who attended SMASSE INSETs were professionally different from the other teachers who did not attend. The ASEI-PDSI movement had been embraced in Vihiga County by teachers of Mathematics. The practice of ASEI-PDSI approach in the teaching and learning of Mathematics yielded improved performance and attitude change. The grand mean on the practice of PDSI was 4.332 on a 5-point Likert scale, considered high. The Mathematics lessons were also activity loaded hence making learning student centered.

\subsection{Recommendations}

Based on these research findings, it can be recommended that:

The teachers who are teaching Mathematics in Vihiga County and have not attended SMASSE INSETs wholly or partially need to be trained in themes and cycles which they have not trained.

Lesson study needs to be re-emphasized to teachers of Mathematics for purposes of instilling confidence in them and improving on the lesson quality.

Further research needs to be conducted in order to establish the impact of SMASSE management at county level on performance of Mathematics and science subjects.

\section{ACKNOWLEDGEMENT}

We are greatly indebted to all Education officers, Principals and teachers of Vihiga County who made this study a success.

\section{REFERENCES}

[1] Bandura, A. (1977). Social Learning Theory. New York: General Learning Press.

[2] Bell, J. (2005). doing your own Research Project: A guide forfirst-time researches in education and social science. Buckingham, Philadelphia: Open University Press. 
[3] Boaler, J. O. (2002): Gender Differences in Mathematics, An Integrative Psychological Approach; California States University San.Bernadino

[4] Cherry, K. (2006). An Overview of Banduras Social Learning Theory. Retrieved October 11, 2012. From Psychology.about.com/od/deveopmentalpsychology/a/sociallearning.htm

[5] Chinelo, O. E. \& Nonye, O. M. (2010). The Use of Effective Communication in Enhancing the Teaching and Learning of School MATHEMATICS. International Research Journals. 1 (10): $432-438$.

[6] Copeland, N. (2009). Research and Statistics. Retrieved October 23, from http://pedsinreview.aapublications.org/cgi/content/full/30/7/278

[7] DEO. (2009). A Vihiga SMASSE Report on Students Achievement in Science and MATHEMATICS at KCSE in the year 2009. (Unpublished).

[8] Diane, P. B. (2003). Using Strategies to Teach Mathematics Skills to Struggling Students. The University of Texas.www.texasreading.org

[9] Dynamic, F. (2007). Effective Communication in the Classroom. Retrieved January 5, 2011 http/www.dynamicflight.com.

[10] Government of the Republic of Kenya. (2007). Kenya Vision 2030. Nairobi.

[11] Harris, N. D. and Sass, R. T. (2007). Teacher Training, Teacher Quality and Students Achievement. Working Paper 3. Pp 1-63.

[12] Hungi, S. K. \& Changeiywo, J. M. (2009). Influence of Creativity Teaching Strategy on Students' Performance and Motivation in the Topic 'Energy' in Secondary School Physics in Nakuru District, Kenya. Journal of Technology and Education in Nigeria. 14(1 \& 2): 101-114.

[13] Indoshi, C. F and Ochanda, J. P. (2011). Challenges and benefits of using scientific calculators in the teaching and learning of Mathematics in secondary school education. Journal of Media and Communication Studies. 3.Pp 102-111.

[14] Inyega, J and Thomson, N (2002). Change in Attitudes towards Teaching Strategies in Secondary School Teachers in Kenya Following In-service Professional Development. Working Draft. University of Georgia

[15] Inzahuli, S. M., Role, E and Makewa, L. N. (2012). Gender Disparities in Self-concept, Attitude and Perception in Physics and Chemistry. .Atlas Journal of Science Education. 2 : 61-69.

[16] Irungu, M. N \& Mugambi, M. (2013). Evaluation of Strengthening of Mathematics and Science in Secondary Education (SMASSE) program. A case study of Murang'a South District, Kenya. International Journal of Education Learning and Development. 1(1). Pp. 46-60.

[17] Johnson, C. (2006). Effective Science Teaching, Professional Development and No Child Left Behind: Barriers, Dilemmas and Reality. Journal of Science Teacher Education 18 (6): 133-136. Retrieved.

[18] Kanja, C., Iwasaki, H., Baba, T and Ueda, A. (2001). For the Reform of Mathematics Education in Kenyan Secondary Schools. Thesis Report.

[19] KNEC. (1996). KCSE Mathematics reports in Kenya, Government Printers, Nairobi. Kenya.

[20] KNEC. (2006). KCSE Mathematics reports in Kenya, Government Printers, Nairobi. Kenya.

[21] KNEC. (2008). KCSE Mathematics reports in Kenya, Government Printers, Nairobi. Kenya.

[22] Kibe, S., Otieno, O and Ateng, O. (2008). Practice of INSET in Mathematics and Science Teachers and its Impact on Quality of Basic Education in Kenya. ADEA. Biennale on Education in Africa. May 5-9, 2008.

[23] Krejcie, R. V., \& Morgan, D. W. (1970). Determining sample size for research activities. Educational and Psychological Measurement. 30. Pp 607-610.

[24] Langat, R. K. (2009). Impact of SMASSE Inset on Students' Attitude and Performance in MATHEMATICS in Secondary Schools in Bomet District. Thesis (M.Phil.) Moi University, Eldoret. http://41.89.160.13:8080/xmlui/handle/123456789/66.

[25] McLeod, S. (2011). Social Learning Theory - Bandura. Retrieved October 11, 2012, From www.mhhe.com/socscience/comm/bandur-s.mhtml

[26] Murphy, L (1996). Gender issues in Mathematics teaching and learning.

[27] National Council of Educational Research and Training. (2006). National Focus Group on Teaching Mathematics. Sri Aurobindo Marg, New Delhi 110016 
[28] National Council of Teachers of MATHEMATICS. (2000). Principles and Standards for School MATHEMATICS, USA

[29] Njuguna, B. M. (1999). The findings from baseline studies by SMASSE Project. SMASSE Project bulletin (unpublished).

[30] Nui, N. W and Wahome, A. N. (2006). SMASSE Project. Tsukuba Journal of Educational Study in MATHEMATICS. 25. 47-56.

[31] Olatoun, A. A. (2012). Resource utilization and internal efficiency in Nigerian secondary schools: Implications for socio problems of education. International Journal of Sociology and Anthropology. 4(1). Pp. 23-30.

[32] Onderi, H. (2009). Continued Professional Development for Secondary School Teachers in the Gucha District of Kenya. Unpublished Thesis. The University of Reading, UK.

[33] Onderi, H. and Malala, G. (2011). A Review on Extent of Sustainability of Educational Projects: A Case of Strengthening Of Mathematics and Science in Secondary Education (SMASSE) Project in Kenya. International Journal of Physical and Social Sciences. 2 (1). Pp 123-144.

[34] Orodho, A. J. (2003). Essentials of Educational and Social Science Research Methods. Nairobi: Mazola Publishers.

[35] Oyaya, E. (2000). Strengthening Mathematics and Sciences in Secondary Education. Unpublished Paper Presented at the Annual Conference of the Kenya National Heads Association held in Nairobi, June 2000.

[36] Republic of Kenya. (2001). Vihiga District Plan. Nairobi: Government Printer.

[37] Robson, C. (2002). Real World Research a Resource for Social Scientists and Practitioner - Researchers. Oxford: Blackwell.

[38] SMASSE, (2008). Records of discussions between Japan International Cooperation Agency and The Government of Kenya on Japanese Technical Cooperation for The Strengthening of Mathematics and Science Education (SMASSE) Project. Government of Kenya Printers. Nairobi, Kenya.

[39] Subramaniam, K (2003). Elementary MATHEMATICS: A Teaching Learning Perspective; Economic and political weekly special issue on the Review of Science Studies; Perspective on MATHEMATICS.

[40] UNESCO. (1992). Report on Education. Paris. UNESCO.

[41] UNESCO SchoolNet, (2003). Final Report, Building Capacity of Teachers/Facilitators in TechnologyPedagogy. Integration for Improved Teaching and Learning. Bangkok, Thailand

[42] Yara, P. O. and Otieno, K. O. (2010).Teaching/Learning Resources and Academic Performance in Mathematics in Secondary Schools in Bondo District of Kenya. Asian Social Science. 6. PP 126-132. 